\title{
Inhibitors of $\mathbf{N}$-glycosylation as a potential tool for analysis of the mechanism of action and cellular localisation of glycoprotein $\mathbf{P}$
}

\author{
Karolina Wojtowicz ${ }^{\bowtie}$, Witold Szaflarski, Radosław Januchowski ${ }^{1}$, Piotr Zawierucha1, \\ Michał Nowicki ${ }^{1}$ and Maciej Zabel ${ }^{1,2}$
}

'Department of Histology and Embryology, Poznan University of Medical Sciences, Poznań, Poland; ²Department of Histology and Embryology, Wroclaw Medical University, Wrocław, Poland

\begin{abstract}
Multidrug resistance has for many years attracted attention of numerous investigators. Attempts have also been made to increase efficiency of anti-neoplastic therapy. For this reason, most of efforts have been devoted to analysing proteins engaged in the mechanism of multidrug resistance such as the $\mathrm{N}$-glycosylated membrane protein glycoprotein P. Interestingly, glycosylation probably plays a significant role in the intracellular location and activity of modified proteins. Inhibitors of glycosylation have been demonstrated to alter the activity of glycoprotein P in various ways, depending on the cell line examined. These inhibitors markedly reduce multidrug resistance of cancer cells, thus promoting success of anti-neoplastic therapy. Here, we review the basic knowledge on $\mathrm{N}$-glycosylation inhibitors, their effect on glycoprotein $\mathrm{P}$ and their therapeutic potential.
\end{abstract}

Key words: $\mathrm{N}$-glycosylation, inhibitors, glycoprotein $\mathrm{P}$, multidrug resistance

Received: 18 May, 2012; revised: 21 September, 2012; accepted: 16 October, 2012; available on-line: 23 October, 2012

\section{INTRODUCTION}

Multidrug resistance (MDR) of cancer cells is one of the main reasons of failure of anti-neoplastic therapy. The phenomenon involves acquisition of resistance neoplastic cells to cytostatic drugs of various groups manifesting distinct chemical structure and mechanism of action by (Gillet \& Gottesman, 2010). Pharmacological agents can cause drug resistance usually when incorrectly dosaged. Another reason involves cellular factors which can change: (1) the rate of absorption of the drug or rate of its elimination from the cell (resistance via transport), (2) the level of activation/inactivation of pharmaceuticals (metabolic resistance), (3) the amount or affinity of enzymes representing target for cytostatic agents (target resistance), (4) the processes of DNA repair, (5) the ability of malignant cells to undergo apoptosis. So far, the best understood mechanism by which drugs are eliminated from the cell is associated with the activity of membrane proteins. The proteins which belong to the superfamily of $\mathrm{ABC}$ transporters are the most important ones in the development of resistance through transport (Sarkadi et al., 2006). Glycoprotein P (P-gp) was the first identified ABC transporter whose hyperactivity of in malignant cells caused resistance (Juliano \& Ling, 1976). Today, it is one of the most intensively investigated protein related to the resistance (Ambudkar et al., 2003). Recently, stud- ies have been performed in order to increase the efficiency of cytostatic drugs by partial or total inhibition of the pumping activity of P-gp causing the resistance. A characteristic feature of MDR proteins is their location in the cell membrane. However, P-gp can also be found in the nuclear envelope (Molinari et al., 2002). This may reflect the existence of additional mechanisms of resistance linked to the cell nucleus. Furthermore, it demonstrates the important role of the intra-cytoplasmic P-gp localization in the transport of drugs into cytoplasmic vesicles which contributes to their transport out of the cells.

Almost forty years of studies on glycoprotein $\mathrm{P}$ have resulted in thorough deciphering of its structure and function. The major findings on P-gp include the following: (1) it is a member of the $\mathrm{ABC}$ transporter family, (2) it is a transmembrane protein, with the $N$-terminus located on the cytoplasmic side of the cell membrane, (3) it consists of two homologous and symmetric transmembrane domains (TMD), encompassing six transmembrane helices and an ATP-binding motif, (4) it undergoes $N$-glycosylation on amino acids 91, 94 and 99 in the first extracellular loop (Molinari et al., 2002; Ambudkar et al., 2003). This protein caries two substrate binding sites. The ATPase activity of P-gp is stimulated by drug binding but a high, basal activity is also observed when a substrate is absent (Sorokin et al., 1999). P-gp demonstrates a high capacity and wide range of substrates, it can transport substrates of diverse chemical character, including antineoplastic drugs, some HIV protease inhibitors, cardiac glycosides, immunosuppressants, corticosteroids, antibiotics, anthracyclines (Marchetti et al., 2007). It has been hypothesized that P-gp can function similar to a flippase - it moves the toxic compounds from the cytoplasm out of the cell where they can diffuse off in the extracellular space (Annese et al., 2006).

$\mathrm{P}$-gp is present in many normal organs, such as kidneys, intestine, adrenal glands, liver, immune system cells, and at a high level in CD34+ haematopoietic stem cells. It is also present in membranes of cell organelles (e.g., lysosomes) and is necessary for their function (Chen et al., 2009). P-gp can be found in endothelial cells of blood vessels in the brain where it is responsible for maintaining of the blood-brain barrier (Annese et al., 2006). In healthy tissues this protein is responsible for

e-mail: k_wojtowicz@onet.pl

Abbreviations: ABC, ATP Binding Cassette superfamily; BFA, brefeldin A; 2-DG, 2-deoxyglucose; DON, 6-diazo-5-oxo-L-norleucine; MDR, multidrug resistance; MRP2, Multidrug Resistance-related Protein 2; P-gp, glycoprotein P; TM, tunicamycin 


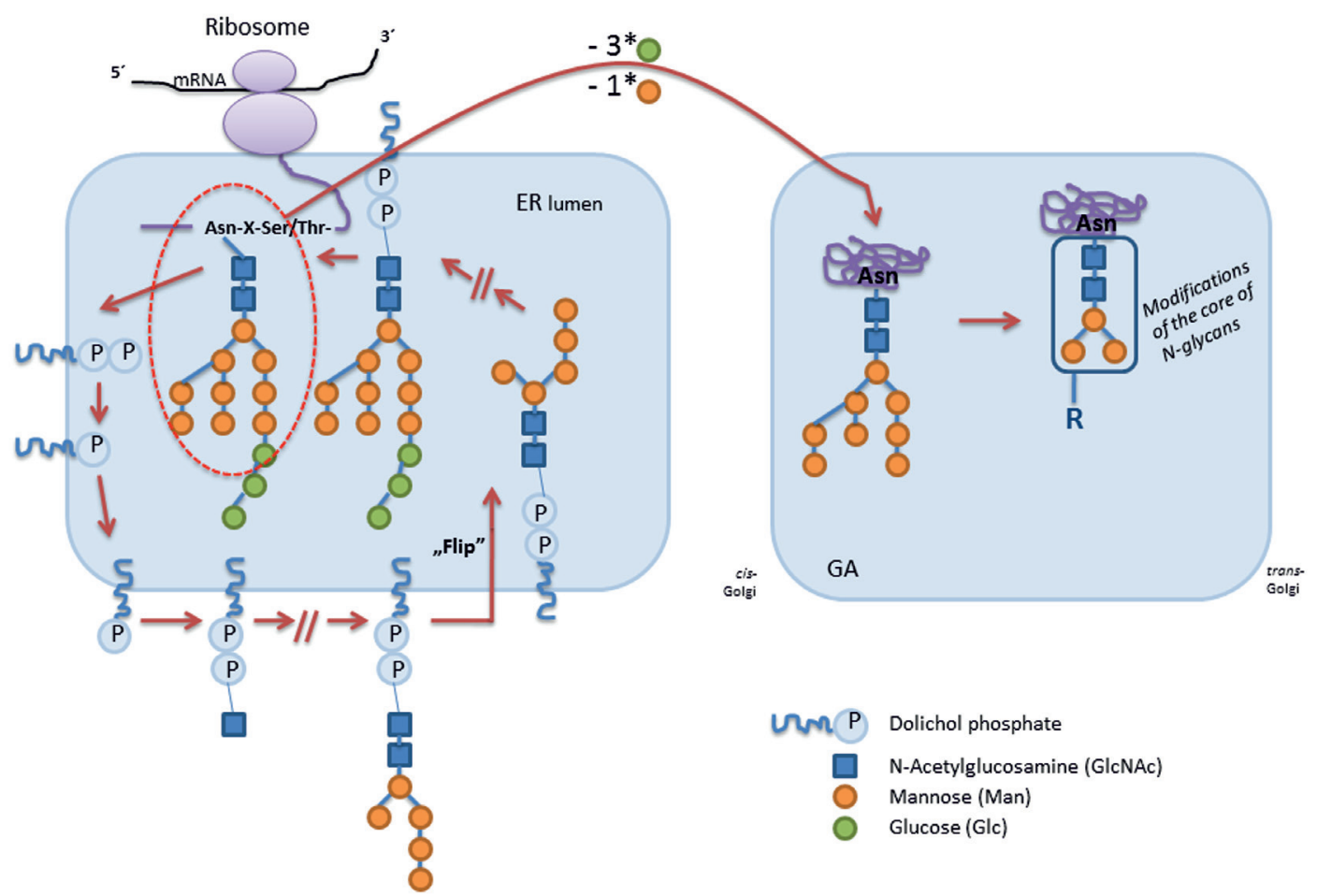

Figure 1. Scheme of $\mathrm{N}$-linked glycosylation, enzymes engaged in the process have been omitted. According to Varki et al., (2009), modified.

Synthesis of sugar core takes place on the dolichol phosphate carrier, first on the cytoplasmic side of endoplasmic reticulum and then in the lumen. The appropriately folded protein enters Golgi apparatus, in which the sugar chain of the glycoprotein becomes further modified (terminal glycosylation).

transport of hormones such as aldosterone and glucocorticoids, and other endogenous molecules (Delou et al., 2009). The overexpression of P-gp can be detected in malignant cells of different origin (kidney tumour, neoplasms of liver, pancreas, intestines, adrenal glands and breast, endothelial cells of newly established capillaries in tumour tissue) (Sorokin et al., 1999).

\section{GENERAL PRINCIPLES OF GLYCOSYLATION}

Glycosylation is a post-translational modification usually associated with secretory and membrane proteins. The sugar residues can be bound covalently to the protein at asparagine residues ( $N$-glycosilation) or at serine/ threonine (O-glycosilation) (Carver \& Dennis, 1995). P-gp undergoes of $N$-linked glycosylation. The first stage of $N$-glycosylation involves synthesis of a sugar core on ER membrane-anchored dolichol phosphate (Fig. 1). Sugar monomers are added from the cytoplasmic side of ER. When a premature sugar core is formed consisting of two residues of $\mathrm{N}$-acetyl-glucosamine and five of mannose, the entire glycan chain is translocated to the luminal side of ER (Ambudkar et al., 2003; Varki et al., 2009). Then, an activated sugar core is formed by addition of four mannose residues and three glucose residues and is finally translocated to an asparagine residue of the target protein. The process of modification is finished when dolichol pyrophosphate is hydrolyzed to dolichol phosphate and becomes ready to accept new sugar monomers (Schwarz \& Aebi, 2011).

The terminal glucoses and mannoses in combination with lectin receptors maintain correct folding of nascent polypeptide and contribute in the elimination of misfolded proteins (Schwarz \& Aebi, 2011). The protein with the sugar core attached is translocated to the Golgi apparatus where terminal glycosylation occurs. The mature protein is finally directed to its final destination (Varki et al., 2009) (Fig. 2).

As mentioned above, glycosylation of P-gp proceeds according to the scheme typical for all $N$-glycans. Human P-gp contains 10 consensus sequences for $N$-linked glycosylation (amino acid sequence: Asn-X-Thr/Ser, where X can be any amino acid except proline) but only three of them are glycosylated, all of them contained in the first extracellular loop of P-gp. P-gp is synthesized as a $140-150 \mathrm{kDa}$ protein and is associated with chaperones (calnexin and Hsc70) in the ER lumen, which is determined by an obscure internal signal sequence near the N-terminal transmembrane domain. The transport signal which mediates the movement of P-gp from ER to Golgi remains unknown, but it can be associated with microtubules. Proteins undergoing the final stages of $N$ glycosylation move though Golgi apparatus from its cis to the trans side, which is also true for P-gp (Schinkel et al., 1992; Fu \& Arias, 2012).

It is hypothesized that the $N$-glycan chain can function as a sorting determinant and thus determine the localization of P-gp. This protein can be delivered to the membrane in vesicles traveling along elements of the cytoskeleton or by an intracellular endosomal system in which protein-containing vesicles are transported to endosomal compartments that support further transport of the protein to the membrane (Fu \& Arias, 2012). The $N$-glycan chains can also contribute to the transloca- 


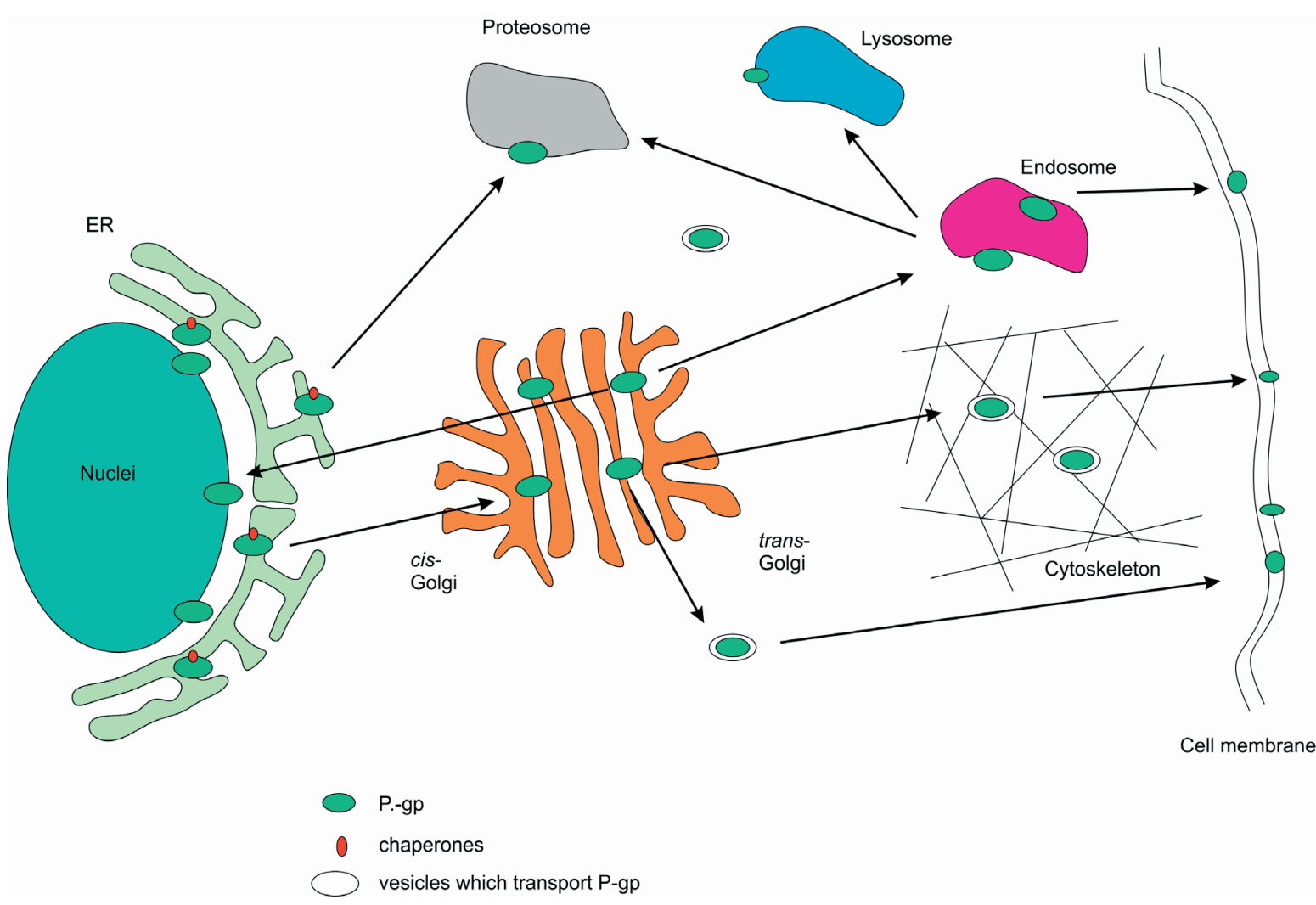

Figure 2. Model of cellular localization of P-gp and possible traffic pathways. According to Fu \& Arias (2012), modified.

$\mathrm{P}$-gp is synthesized in ER and is associated with chaperones (calnexin and Hsc70) during folding. The cis-Golgi receives P-gp from ER, in the trans-Golgi the glycoprotein matures. The protein can be delivered to the membrane in vesicles which move on the cytoskeleton or by an intracellular endosomal system, and then the protein can be transport to the membrane and other cell organelles. P-gp can also be transferred to the nucleus.

tion of glycosylated protein to the nucleus. Such a protein might be transferred to the nucleus through nuclear pores by conventional nuclear transport pathways (Varki et al., 2009) (Fig. 2), which is supported by detection of glycoprotein $\mathrm{P}$ in the nuclear envelope (Molinari et al., 2002). It would be very interesting to check whether the P-gp from the nuclear envelope differs from its cytoplasmatic counterpart in respect to the composition of the glycan attached.

\section{INHIBITORS OF N-LINKED GLYCOSYLATION}

It has been demonstrated that the type of sugar core attached probably determines the intracellular target of the modified protein as well as enhances its folding and stability during transport (Busc et al., 1995; Walsh et al., 1998; Zhou et al., 2005; Straummann et al., 2006; Varki et al., 2009, Draheim et al., 2010; Nakajima et al., 2010). The glycosylated protein can be translocated to a wide spectrum of cellular compartments such as Golgi apparatus, mitochondria and nucleus. P-gp undergoes $N$ linked glycosylation with various combination of sugar core which probably determines the protein function and its destination. Experiments with cDNA encoding $N$-glycosylation-deficient P-gp showed that P-gp without the glycan is stuck in subcellular compartments (Draheim et al., 2010).

Kramer et al. (1995) showed that tunicamycin (one of the best known inhibitors of glycosylation) suppressed P-gp activity with subsequent accumulation of cytostatic drugs in the cells. This finding was a proof that inhibitors of glycosylation are able to eliminate the MDR phenotype caused by P-gp. Furthermore, only fully $N$-glycosylated ABC transporters were active in sandwich-cultured rat hepatocytes (Draheim et al., 2010). Point mutations or expression in the presence of proteasome inhibitor prevented P-gp from folding into the mature protein. Human P-gp does not form functional transporter immediately after synthesis but it requires additional folding to be active (Loo \& Clarke, 1999). It is another evidence that the presence of the glycan chain is essential for P-gp activity. However, in some studies no direct effect of the glycan residue was demonstrated on the transport activity of P-gp (Šereš et al., 2011). Schinkel and coworkers (1993) showed also that $N$-glycosylation could influence P-gp maturation and stability but not drug transport. They mutated one, two or all three glycosylation sites present in human P-gp and showed that the absence of N-glycosylation did not impact the level of drug resistance of cells and the $N$-glycosylation was not necessary for P-gp function, although its absence significantly reduced the ability to form drug-resistant clones. Another group showed that the inhibition of P-gp $N$-glycosylation did not change its localization in the cell membrane and its transport activity. On the other hand, the inhibition of glycosylation caused higher ubiquitination and degradation of P-gp (Kramer et al., 1993a; Šereš et al., 2011). These data remain to be clarified.

Schinkel and coworkers (1993) claims that N-glycosylation may stabilize correct folding of P-gp, ensure its correct subsellular localization and protect from degradation by luminal proteases. Altogether, these data indicate that the glycan chain does not affect the 
function of P-gp but rather helps direct the protein to its correct intracellular destination, which is important for its pumping activity.

Studies on the role of the P-gp-attached sugar residues concern also inhibitors of glycosylation which block its particular stages (Elbein, 1991; Jacob, 1995). Most of the studies were performed using only one inhibitor of $N$-glycosylation, tunicamycin. However, a number of various inhibitors exist categorized by their mechanism of action and target. They may block N-glycosylation through: (1) interference with the turnover of the process precursors, (2) inhibition of glycosylases, (4) inhibition of transport of modified proteins between cellular compartments engaged in $N$-glycosylation, i.e. endoplasmic reticulum, Golgi apparatus, and (5) functioning as substrate analogues (Dennis et al., 1997; Varki et al., 2009). Below, we review so far known inhibitors of $N$ glycosylation.

\section{Metabolic inhibitors}

They affect the turnover of glycosylation precursors, mainly at the stage of their formation. A fairly well recognized glutamine analogue is 6-diazo-5-oxoL-norleucine (DON) which blocks glutamine:fructose6-phosphate aminotransferase, an enzyme engaged in the synthesis of glucosamine from glutamine and fructose. Such a block results in a decreased production of glucosamine, a basic precursor of the main glycan component (Datta \& Dasgupta, 1994; Brasse-Lagnel et al., 2003; Varki et al., 2009). It has been shown that DON inhibits viral RNA synthesis (Datta \& Dasgupta, 1994). DON has variable effects on different types of tumour cells, but in most cases it results in disruption of mitochondrial internal membrane structures, autophagocytosis of secretory granules, swelling of the endoplasmic reticulum, induces apoptosis, somatic crossing over and point mutations (Wu et al., 1999).

Brefeldin A (BFA) is another example of a glycosylation inhibitor: it is a macrocyclic lactone synthesized from palmitate by various fungi. As compared to the earlier example, BFA acts at a later stage of glycosylation, inducing an inverse transport of components in the Golgi apparatus, it inhibits the early transport of proteins from the endoplasmic reticulum to the Golgi apparatus (Klausner et al., 1992). BFA leads to a damage of the physical separation of ER and Golgi compartments by allowing membrane fusion to occur in the absence of the earlier vesicle formation. BFA also disrupts organization of the microtubule and actin cytoskeletons (Nebenfuhr et al., 2002).

\section{Sugar analogues}

Their mechanism of glycosylation inhibition involves mainly blocking of enzymes, glycosyltransferases, which transfer saccharides from an active donor to a specific acceptor group. As a consequence, the sugar is not transferred to the nascent glycoprotein and further branching of the sugar core is not possible. An example of such inhibitors (which is also an inhibitor of glycolysis) is 2-deoxyglucose (2-DG), the presence of which in a cell leads to the formation of dolichol-P-2-deoxyglucose which cannot be further extended, so the attachment of consecutive sugars and their transfer to the protein is impossible (Dwarakanath, 2009; Gaddameedhi \& Chatterjee, 2009; Andresen et al., 2012). 2-DG has an impact on gene expression, phosphorylation of proteins involved in signalling pathways, it blocks the cell cycle progression,
DNA repair and finally leads to apoptosis. Studies in vitro have shown that this compound stops cancer cell proliferation and leads to their apoptosis and such a cytotoxic effect is stronger in hypoxia and upon a knockdown of HIF-1 (hypoxia-inducible transcription factor vital to cancer development). Recently, it was observed that 2-DG leads to apoptosis independently of Bcl-2 and its cytotoxic effect does not correlate with p53 status in many malignant cells (Dwarakanath, 2009).

\section{Glycoside primers}

Glycoside primers represent a group of compounds which block synthesis of glycosaminoglycans on growing proteoglycans. They redirect the process of glycoprotein assembly: instead of the endogenous glycoprotein core, subsequent sugar moieties elongate the chain formed by exogenous ,primers”, which results in premature inhibition of glycan synthesis. The best known compound of this class, discovered around 40 years ago, is $\beta$-Dxyloside (Lugemwa et al., 1996). This molecule shows higher ability to penetrate the cell membrane than other inhibitors (Varki et al., 2009). Many publications have demonstrated its power as an anti-thrombin, anti-platelet and anti-thrombotic factor (Toomey et al., 2006). However, $\beta$-D-xyloside inhibits also proliferation of different cell types because it arrests cells in the G1 phase of the cell cycle, although the effect is rapidly reversed (PotterPerigo et al., 1991).

\section{Plant alkaloids}

Plant alkaloids are natural inhibitors of glycosidases which block elongation of sugar chains. The inhibition occurs only at a specific stage of glycosylation, following formation of a 14 monomer-long chain ( $\mathrm{Glc}_{3} \mathrm{Man}-$ ${ }_{9} \mathrm{GlcNAc}_{2}$ ) and thus plant alkaloids block formation of mature glycoprotein. Castanospermine, isolated from the Australian chestnut tree Castanosperum australe, inhibits $\alpha$-glycosidase I and II (Marchal et al., 1999; Varki et al., 2009). Two other equally well known inhibitors of this class, australine and deoxynojirimycin, block only one of these enzymes (Varki et al., 2009; Zhao et al., 2010). Castanospermine induces accumulation of fully glycosylated chains which are designated to bind the protein under modification. Castanospermine and deoxynojirimycin also inhibit angiogenesis in vitro (Zhao et al., 2010). Cells treated with castanospermine carry a lower number of receptors which contain glycan, e.g., LDL receptors and insulin receptor on lymphocytes. Castanospermine was also shown to inhibit viral replication and maturation of HIV. Deoxynojirimycin blocks IgG secretion. Australine is a plant alkaloid which probably interferes with formation of specific $N$-linked glycoprotein but these data have still to be confirmed (Elbein, 1991).

Swainsonine is another very interesting compound which blocks $\alpha$-mannosidase II and lysosomal $\alpha$-mannosidase. This alkaloid protects some plants against insects and herbivorous animals. It has a neurotoxic effect („syndrome loco") and the intoxication with it results in accumulation of glycoproteins in lymph nodes (Carver et al., 1995; Varki et al., 2009). Swainsonine probably does not affect the function of the N-glycosylated proteins. However, it blocks the metastasis of murine melanoma cells by enhancing natural killer cell proliferation or their anti-tumour activity (Elbein, 1991). The drug also induces T-cell activation (Jacob, 1995). 


\section{Antibiotics}

Tunicamycin (TM) is the best known and the most frequently applied inhibitor of $N$-glycosylation. It was isolated for the first time from Streptomyces lysosuperificus in 1973, while the name reflects its antiviral activity, i.e., inhibition of viral coat ("tunica") synthesis. It is a nucleoside antibiotic whose mechanism of action involves blocking of the enzyme responsible for the transfer of 1-phospho-N-acetylglucosamine from UDP-N-acetylglucosamine to dolichol phosphate, i.e., the first glycosylation stage. The cytotoxic effect of tunicamycin on cells induces apoptosis also in neoplastic cells (Carver \& Dennis, 1995; Lugemwa et al., 1996; Marchal et al., 1999; Molinari et al., 2002; Delom et al., 2007; Gaddaneedhi \& Chatterjee, 2009; Varki et al., 2009; Zhao et al., 2010; de Freitas et al., 2011). In melanoma cells, TM leads to apoptosis after $24-48 \mathrm{~h}$ from its induction. The mechanism of TM action is not fully known but it involves simultaneous increasing the level of $\mathrm{Ca}^{2+}$ and decreasing the effect of insulin-like growth factor I (IGF-I) because of a down-regulation of IGF-I receptor on the cell surface (Dricu et al., 1997). Hiss and coworkers (2007) showed that tunicamycin enhanced toxicity of antineoplastic drugs in multidrug-resistant human ovarian cystadenocarcinoma cells. It significantly reduced $\mathrm{IC}_{50}$ for doxorubicin and vincristine. This sheds a new light on cancer treatment and gives hope for increasing its effectiveness. Tunicamycin decreased $\mathrm{IC}_{50}$ also for cisplatin in human head-and-neck carcinoma cells. In vitro studies on TM and cisplatin showed that it effectively blocked local tumour growth in a cisplatin-resistant mouse model (Noda et al., 1999).

Bacitracin is an antibiotic blocking dolichol pyrophosphate hydrolysis to dolichol phosphate which, as a consequence, disables glycoprotein synthesis at its first stage (Molinari et al., 2002). Bacitracin induces disruption of ER function and causes higher ER stress-mediated apoptosis in melanoma cells characterized by the up-regulation of ER chaperones leading to damage repair (Lovat et al., 2008).

\section{SUMMARY}

Inhibitors of glycosylation have been subjected to numerous tests for many years and they draw a growing attention of scientists. They have been proven to find a very broad application as potential therapeutic tools. The cancer patients manifest a higher intensity of glycosylation and some proteins are charged with glycan cores branched more extensively than in healthy individuals (Dricu et al., 1997; Liu et al., 2001). Therefore, blocking glycosylation may be crucial in the treatment of cancer. It is worth remembering that the mentioned inhibitors also exert positive effects in treatment of diabetes mellitus, AIDS, and may also induce male infertility (Molinari et al., 2002). But, a lot of attention is given to them in the context of their application to increase efficacy of chemotherapy (Walsh et al., 1998; Zhou et al., 2005). Currently, one of the major problems of effective chemotherapy is multidrug resistance of cancer cells. Proteins of key importance for multidrug resistance, glycoprotein P, MRP1 and MRP2, undergo glycosylation. This type of post-translational modification is likely to be crucial for the cellular localization of glycoprotein P, discussed in this manuscript. As for the participation of $N$-linked glycosylation in the activity of P-gp, scientists express contradictory opinions. It is quite probable that the distinct effects of tunicamycin and other inhibitors on the transporting activity of glycoprotein $\mathrm{P}$ reflects the type of cell line used in particular studies (Loo \& Clarke, 1998; Ledoux et al., 2003; Zhang et al., 2004; Hiss et al., 2007; Šereš et al., 2011). Therefore, in order to verify this information, it would be worthwhile to perform a series of studies using various inhibitors of glycosylation and different cell lines. Thus, it would be possible to verify the opinion that the glycan residues are important for the activity and cellular localization of P-gp. There is no doubt that inhibitors of glycosylation may be a promising therapeutic approach. Examples described here show that inhibitors of $N$-glycosylation enhance the cytotoxic effect of drugs on cells showing a multidrug resistance while in normal cells they induce apoptosis. However, most of these studies have not examined the effect of inhibitors in the context of MDR proteins, including glycoprotein $\mathrm{P}$, but the data may be very important in the treatment of cancer (Molinari et al., 2002). In our opinion, glycosylation of P-gp may have a significant effect on its transport activity.

The available literature data show that inhibitors of $N$-linked glycosylation may be a potential tool for analysis of the mechanism of action and cellular location of P-gp. The question requires broader investigations. If the hypothesis that inhibition of P-gp N-glycosylation leads to more effective chemotherapy is confirmed, this approach may bring a revolution in anti-neoplastic therapy (Bebtley et al., 1997; Noda et al., 1999; Gribar et al., 2000; Ohtsubo \& Marth, 2006; Contessa et al., 2010; Grosso et al., 2011).

\section{Acknowledgements}

Financial support: National Science Centre (project no. 0172/B/P01/2009/36).

\section{REFERENCES}

Ambudkar SV, Kimchi-Sarfaty C, Sauna ZE, Gottesman MM (2003) P-glycoprotein: from genomics to mechanism. Oncogene 22: 74687485.,3

Andresen L, Skovbakke SL, Persson G, Hagemann-Jensen M, Hansen KA, Jensen H, Skov S (2012) 2-Deoxy D-glucose prevents cell surface expression of NKG2D ligands through inhibition of $n$-linked glycosylation. J Immunol 188: 1847-1855.

Annese V, Valvano MR, Palmieri O, Latiano A, Bossa F, Andriulli A (2006) Multidrug resistance 1 gene in inflammatory bowel disease: A meta-analysis. World J Gastroenterol 12: 3636-3644.

Bentley J, Quinn DM, Pitman RS, Warr JR, Kellett GL (1997) The human $\mathrm{KB}$ multidrug-resistant cell line $\mathrm{KB}-\mathrm{Cl}$ is hypersensitive to inhibitors of glycosylation. Cancer Lett 115: 221-227.

Brasse-Lagnel C, Fairand A, Lavoinne A, Husson A (2003) Glutamine stimulates argininosuccinate synthetase gene expression through cytosolic O-glycosylation of Sp1 in Caco-2 Cells. J Biol Chem 278: 52504-52510.

Buscà PR, Pujana MA, Pognonec P, Auwerx J, Deeb SS, Reina M, Vilaró S (1995) Absence of $N$-glycosylation at asparagine 43 in human lipoprotein lipase induces its accumulation in the rough endoplasmic reticulum and alters this cellular compartment. I Lipid Res 36: 939-951.

Carver JP, Dennis JW (1995) Inhibitors of carbohydrate processing: a new class of anticancer agents. Clin Cancer Res 1: 935-944.

Chen K, Valencia J, Gillet J, Hearing V, Gottesman M (2009) Involvement of $\mathrm{ABC}$ transporters in melanogenesis and the development of multidrug resistance of melanoma. Pigment Cell Melanoma Res 22: $740-749$.

Contessa JN, Bhojani MS, Freeze HH, Ross BD, Rehemtulla A, Lawrence TS (2010) Molecular imaging of $N$-linked glycosylation suggests glycan biosynthesis is a novel target for cancer therapy. Clin Cancer Res 16: 3205-3214.

Datta U and Dasgupta A (1994) Expression and subcellular localization of poliovirus VPg-precursor protein $3 \mathrm{AB}$ in eukaryotic cells: evidence for glycosylation in vitro. I Virol 68: 4468-4477.

de Freitas JCM, D'Aguiar Silva BDR, de Souza WF, de Arau' jo WM, Abdelhay ESFW, Morgado-D1'az JA (2011) Inhibition of $N$-linked glycosylation by tunicamycin induces E-cadherin-mediated cell-cell 
adhesion and inhibits cell proliferation in undifferentiated human colon cancer cells. Cancer Chemother Pharmacol 68: 227-238.

Delom F, Emadali A, Cocolakis E, Lebrun JJ, Nantel A, Chevet E (2007) Calnexin-dependent regulation of tunicamycin induced apoptosis in breast carcinoma MCF-7 cells. Cell Death Differ 14: 586-596.

Delou J, Lopes A, Capella M, Delou J (2009) Unveiling the role of multidrug resistance proteins in hypertension. Hypertension 54: 210 216.

Dennis JW, Granovsky M, Warren CE (1999) Protein glycosylation in development and disease. BioEssays 21: 412-421.

Draheim V, Reichel A, Weitschies W, Moenning U (2010) N-glycosylation of $\mathrm{ABC}$ transporters is associated with functional activity in sandwich-cultured rat hepatocytes. Eur J Pharm Sci 41: 201-209.

Dricu A, Carlberg M, Wang M, Larsson O (1997) Inhibition of $N$ linked glycosylation using tunicamycin causes cell death in malignant cells: role of down-regulation of the insulin-like growth factor 1 receptor in induction of apoptosis. Cancer Res 57: 543-548.

Dwarakanath BS (2009) Cytotoxicity, radiosensitization, and chemosensitization of tumor cells by 2-deoxy-D-glucose in vitro. J Cancer Res Ther 5: S27-S31.

Elbein AD (1991) Glycosidase inhibitors: inhibitors of $N$-linked oligosaccharide processing. FASEB J 5: 3055-3063.

Fu D, Arias IM (2012) Intracellular trafficking of P-glycoprotein. Int J Biochem Cell Biol 44: 461-464.

Gaddameedhi S, Chatterjee S (2009) Association between the unfolded protein response, induced by 2-deoxyglucose, and hypersensitivity to cisplatin: a mechanistic study employing molecular genomics. I Cancer Res Ther 5: S61-S66.

Gillet JP, Gottesman MM (2010) Mechanisms of multidrug resistance in cancer. Methods Mol Biol 596: 47-76.

Gribar JJ, Ramachandra M, Hrycyna CA, Dey S, Ambudkar SV (2000) Functional characterization of glycosylation-deficient human p-glycoprotein using a vaccinia virus expression system. J. Membrane Biol 173: 203-214.

Grosso FD, Mariano MD, Passoni L, Luksch R, Tonini GP, Longo L (2011) Inhibition of $N$-linked glycosylation impairs ALK phosphorylation and disrupts pro-survival signaling in neuroblastoma cell lines. BMC Cancer 11: 525.

Hiss DC, Gabriels GA, Folb PI (2007) Combination of tunicamycin with anticancer drugs synergistically enhances their toxicity in multidrug-resistant human ovarian cystadenocarcinoma cells. Cancer Cell Int 7: 5 .

Jacob GS (1995) Glycosylation inhibitors in biology and medicine. Curr Opin Struct Biol 5: 605-611.

Juliano RL, Ling V (1976) A surface glycoprotein modulating drug permeability in Chinese hamster ovary cell mutants. Biochim Biophys Acta 455: 152-162.

Klausner RD, Donaldson JG, Lippincott-Schwartz J (1992) Brefeldin A: insights into the control of membrane traffic and organelle structure. J Cell Biol 116: 1071-1080.

Kramer R, Weber TK, Morse B, Arceci R, Staniunas R (1993) Constitutive expression of multidrug resistance in human colorectal tumors and cell lines. Br J Cancer 67: 959-968.

Kramer R, Weber TK, Arceci R, Ramchurren N, Kastrinakis MV, Steele G Jr, Summerhayes IC (1995) Inhibition of N-linked glycosylation of $\mathrm{P}$-glycoprotein by tunicamycin results in a reduced multidrug resistance phenotype. Br J Cancer 71: 670-675.

Ledoux S, Yang R, Friedlander G, Laouari D (2003) Glucose depletion enhances P-glycoprotein expression in hepatoma cells: role of endoplasmic reticulum stress response. Cancer Res 63: 7284-7290.

Liu YY, Han TY, Giuliano AE, Cabot MC (2001) Ceramide glycosylation potentiates cellular multidrug resistance. FASEB J 15: 719-730.

Loo TW, Clarke DM (1998) Quality control by proteases in the endoplasmic reticulum. Removal of a protease-sensitive site enhances expression of human P-glycoprotein. J Biol Chem 273: 32373-32376.

Loo TW, Clarke DM (1999) The human multidrug resistance P-glycoprotein is inactive when its maturation is inhibited: potential for a role in cancer chemotherapy. FASEB J 13: 1724-1732.

Lovat PE, Corazzari M, Armstrong JL, Martin S, Pagliarini V, Hill D, Brown AM, Piacentini M, Birch-Machin MA, Redfern CPF (2008) Increasing melanoma cell death using inhibitors of protein disulphide isomerases to abrogate survival responses to endoplasmic reticulum stress. Cancer Res 68: 5363-5369.
Lugemwa FN, Sarkar AK, Esko JD (1996) Unusual $\beta$-D-xylosides that prime glycosaminoglycans in animal cells. J Biol Chem 271: 1915919165.

Marchal I, Mir AM, Kmiécik D, Verbert A, Cacan R (1999) Use of inhibitors to characterize intermediates in the processing of $N$-glycans synthesized by insect cells: a metabolic study with Sf9 cell Line. Glycobiology 9: 645-654.

Marchetti S, Mazzanti R, Beijnen J, Schellens J (2007) Clinical relevance of drug-drug and herb-drug interactions mediated by the ABC transporter ABCB1 (MDR1, P-glycoprotein). The Oncologist 12: 927-941.

Molinari A, Calcabrini A, Meschini S, Stringaro A, Crateri P, Toccacieli L, Marra M, Colone M, Cianfriglia M, Arancia G (2002) Subcellular detection and localization of the drug transporter P-glycoprotein in cultured tumor cells. Curr Protein Pept Sci 3: 653-670.

Nakajima M, Koga T, Sakai H, Yamanaka H, Fujiwara R, Yokoi T (2010) N-Glycosylation plays a role in protein folding of human UGT1A9. Biochem Pharmacol 79: 1165-1172.

Nebenfuhr A, Ritzenthaler C, Robinson DG (2002) Brefeldin A: Deciphering an Enigmatic Inhibitor of Secretion. Plant Physiology 130: 1102-1108.

Noda I, Fujieda S, Mizue Seki M, Tanaka N, Sunaga H, Ohtsubo T, Tsuzuki H, Fan GK, Saito H (1999) Inhibition of N-linked glycosylation by tunicamycin enhances sensitivity to cisplatin in human head-and-neck carcinoma cells. Int J Cancer 80: 279-284.

Ohtsubo K, Marth JD (2006) Glycosylation in Cellular Mechanisms of Health and Disease. Cell 126: 855-867.

Potter-Perigo S, Braun KR, Schönherr E (1991) Altered proteoglycan synthesis via the false acceptor pathway can be dissociated from $\beta$-d-xyloside inhibition of proliferation. Arch Biochem Biophys 297: 101-109.

Sarkadi B, Homolya L, Szakàcs G, Vàradi A (2006) Human multidrug resistance $\mathrm{ABCB}$ and $\mathrm{ABCG}$ transporters: participation in a chemoimmunity defense system. Physiol Rev 86: 1179-1236.

Schinkel AH, Kemp S, Dolle M, Rudenko G, Wagenaar E (1992) NGlycosylation and deletion mutants of the human MDR1 P-glycoprotein. J Biol Chem 268: 7474-7481.

Schwarz F, Aebi M (2011) Mechanisms and principles of N-linked protein glycosylation. Curr Opin Struct Biol 21: 576-582.

Šereš M, Cholujová D, Bubenčíkova T, Breier A, Sulová Z (2011) Tunicamycin depresses P-glycoprotein glycosylation without an effect on its membrane localization and drug efflux activity in L1210 Cells. Int J Mol Sci 12: 7772-7784.

Sorokin D, Duś D (1999) Role of P-gp and other transport proteins in multidrug resistance. Nowotwory 49: 573-581 (in Polish).

Straumann N, Wind A, Leuenberger T, Wallimann T (2006) Effects of N-linked glycosylation on the creatine transporter. Biochem J 393: 459-469.

Toomey JR, Abboud MA, Valocik RE, Koster PF, Burns-Kurtis CL, Pillarisetti K, Danoff TM, Erhardt JA (2006) A comparison of the $\beta$-D-xyloside, odiparcil, to warfarin in a rat model of venous thrombosis. I Thromb Haemost 4: 1989-1996.

Varki A, Cummings RD, Esko JD, Freeze HH, Stanley P, Bertozzi CR, Hart GW, Etzler ME, eds (2009) Essentials of Glycobiology. 2nd edn. Cold Spring Harbor (NY): Cold Spring Harbor Laboratory Press.

Walsh MT, Foley JF, Kinsella BT (1998) Characterization of the role of $N$-linked glycosylation on the cell signaling and expression of the human thromboxane $\mathrm{A}_{2}$ Receptor Alpha and Beta Isoforms. JPET 286: 1026-1036.

Wu F, Lukinius A, Bergström M, Eriksson B, Watanabe Y, Längström B (1999) Eur J Cancer 35: 1155-1161.

Zhang Z, Wu JY, Hait WN, Yang JM (2004) Regulation of the stability of P-glycoprotein by ubiquitination. Mol Pharmacol 66: 395-403.

Zhao Y, Zhou Y, O' Boyle KM, Murphy PV (2010) Biological study of the angiogenesis inhibitor N-(8-(3-ethynylphenoxy)octyl-1-deoxynojirimycin. Chem Biol Drug Des 75: 570-577.

Zhou F, Xu W, Hong M, Pan Z, Sinko PJ, Ma J, You G (2005) The role of $N$-linked glycosylation in protein folding, membrane targeting, and substrate binding of human organic anion transporter hOAT4. Mol Pharmacol 67: 868-876. 